ren a waren die Kulturen beider Serum-Gruppen in schlechterem Gesundheitszustand als die Vergleichsgruppe ohne Serumzusatz.

\section{Diskussion}

Aus den Ergebnissen der Versuchsabschnitte I und II ist zu folgern, daß in Benzpyren-Sarkomen bei Ratten keine Antigenpotenzen vorhanden sind, die sich von den antigenen Art- oder Gewebseigenschaften des tumorfreien Organismus so sehr unterscheiden, daß zirkulierende Antikörper gegen sie gebildet werden. Diese Aussage kann jedoch nur im Zusammenhang mit der Reichweite der angewandten serologischen Methoden und deren Empfindlichkeit verstanden werden, Das heißt, daß sich unsere Befunde nur auf das Vorkommen von Ambozeptoren, Präzipitinen- Zytotoxinen und die mit der Kolloid-Komplementbindungs-Reaktion nachweisbaren, univalen-

21 A. D. Dunlay, V. Goldsmith, K. Arnesen u. L. Buxton, Can cer Res. 9, 217 [1949].

22 E. Edlinger u. L. Harel, Bull. Cancer 41, 363 [1954].

23 E. Edinger u. F. Lacour, Bull. Cancer 42, 382 [1955].

24 H. N. Green, Ber. allg. spez. Pathol. 41, 38 [1959].

25 R. A. Malmaren, J. nat. Cancer Inst. 20, 417 [1958]. ten Antikörper beziehen. Es gibt z. B. reaktive Vorgänge im Organismus gegenüber antigenen Substanzen, bei denen im allgemeinen keine Antikörper im Blut auftreten. Von unseren Versuchsergebnissen kann deshalb nichts Grundsätzliches über die Rolle von Immunreaktionen in der Tumorpathogenese abgeleitet werden.

Unsere Ergebnisse können in die unter anderem von Dunlay und Mitarbb. ${ }^{21}$, Edlinger und Harel ${ }^{22}$, Edlinger und Lacour ${ }^{23}$, Green ${ }^{24}$, Malmgren ${ }^{25}$, Malmgren und Mitarbb. ${ }^{26,27}$, Schmidt und Mitarbb. ${ }^{28}$ und WeILER ${ }^{29}$ mitgeteilten Befunde eingereiht werden, in denen von den Autoren gegen neoplastisches Gewebe keine tumorspezifischen, zirkulierenden Antikörper nachgewiesen werden konnten, bzw. von ihnen sogar ein Antigenverlust des Tumors gegenüber dem Normalgewebe festgestellt wurde ${ }^{24.29}$.

26 R. A. Malmgren u. B. E. Bennison, J. nat. Cancer Inst. 11, 301 [1950].

27 R. A. Malmgren, B. E. Bennison, B. F. Anderson u. C. C. Risley, J. nat. Cancer Inst. 11, 1277 [1951].

28 F. Schmidt, E. Liss u. R. Coutelle, Z. Krebsforsch. 62, 658 [1959].

29 E. WeIler, Strahlentherapie 93, 213 [1954].

\title{
Umwandlung des embryonalen Stoffwechsels in Krebsstoffwechsel
}

\author{
Von Otto Warburg, Karlfried Gawehn und August-Wilhelm Geissler \\ Aus dem Max-Planck-Institut für Zellphysiologie, Berlin-Dahlem \\ (Z. Naturforschg. 15 b, 378-379 [1960]; eingegangen am 28. März 1960)
}

\begin{abstract}
Der Stoffwechsel der embryonalen Hühnerzellen ist ein reiner Oxydations-Stoffwechsel. Bei der Kultur in vitro unter Zusatz von Serum schlägt der embryonale Stoffwechsel in $48 \mathrm{Stdn}$. in den Gärungsstoffwechsel der Krebszellen um.
\end{abstract}

10-tägige Hühnerembryonen wurden nach DuLBEcco-VogT ${ }^{1}$, wie früher für Nierenzellen beschrieben ${ }^{2}$, trypsinisiert, gewaschen und mit Nährmedium + Serum auf das 400-fache des Zellvolumens verdünnt. Der Bicarbonatgehalt betrug dann etwa $400 \mathrm{~mm}^{3} \mathrm{NaHCO}_{3}$ pro $\mathrm{cm}^{3}$. Diese Zellsupension wurde in Petrischalen von $10 \mathrm{~cm}$ Durchmesser gegossen und in einer Atmosphäre von $5 \mathrm{Vol}-\% \mathrm{CO}_{2}$-Luft bei $38^{\circ}$ gezüchtet, wobei etwa ${ }^{1} / 3$ der Zellen am Boden der Schalen anwächst und sich hier in Form von Spindelzellen teilt, während die übrigen Zellen absterben und sich z. T. auflösen. Die gewachsenen Zellen wurden nach 24 oder 48 Stdn. mit wenig Versen und Trypsin vom Boden der Schalen abgelöst, in Phosphat-Salzlösung gewaschen und zur Stoff- wechselmessung wieder in Kulturlösung + Serum aufgenommen, der noch Bicarbonat und Glucose bis zur physiologischen Konzentration zugesetzt war. Bei der Manometrie fanden wir:

Aus dem embryonalen Stoffwechsel (Zeit Null der Züchtung)

$$
\begin{array}{cccc}
Q_{\mathrm{O}_{2}} & Q_{\mathrm{MI}}^{\mathrm{O}_{2}} & Q_{\mathrm{M}}^{\mathrm{Argon}} & \begin{array}{c}
\text { M e y e r h of }- \\
\text { Quotient }
\end{array} \\
-12 & 0 & +15 & 1,25
\end{array}
$$

entstand bei der Züchtung in vitro (unter Zusatz von Serum) in 48 Stdn. der folgende Stoffwechsel:

1 R. Dulbecco u. M. Vogt, J. exp. Medicine 99, 167 [1954].

2 O. WarburG, K. Gawehn u. A. W. Geissler, Z. Naturforschg. 13 b, 588 [1958]. 


\begin{tabular}{|c|c|c|c|c|c|}
\hline Kulturmedium & $\begin{array}{c}\text { Züchtungsdauer } \\
\text { [Stdn.] }\end{array}$ & $Q_{\mathbf{O}_{\mathbf{3}}}$ & $Q_{\mathrm{M}}^{\mathbf{O}_{\mathbf{2}}}$ & $Q_{\mathrm{M}}^{\text {Argon }}$ & $M Q$ \\
\hline$+50 \%$ inaktiviertes Kälberserum & 24 & $-6,8$ & +18 & +46 & 4,1 \\
$+50 \%$ inaktiviertes Kälberserum & 48 & -2 bis -4 & $+34,6$ & $+49,6$ & $3,8-7,5$ \\
$+50 \%$ inaktiviertes Kälberserum & 24 & -11 & $+10,6$ & +40 & 2,7 \\
$+50 \%$ inaktiviertes Kälberserum & 48 & -6 & $+20,6$ & +50 & 5,0 \\
$+50 \%$ frisches Hühnerserum & 24 & $-11,5$ & $+5,2$ & $+37,8$ & 2,8 \\
$+50 \%$ frisches Hühnerserum & 48 & $-11,4$ & $+12,5$ & $+38,7$ & 2,3 \\
$+50 \%$ frisches Hühnerserum & 24 & -11 & $+3,4$ & $+37,4$ & 3,1 \\
$+50 \%$ frisches Hühnerserum & 48 & $-8,3$ & +11 & $+44,2$ & 4,0 \\
\hline
\end{tabular}

Wir fanden also für die im Körper gewachsenen embryonalen Zellen einen reinen Oxydationsstoffwechsel, für die in vitro mit Kälberserum gewachsenen Zellen nach $48 \mathrm{Stdn}$. voll ausgebildeten Krebsstoffwechsel. Dieser Krebsstoffwechsel kann nicht in einem kleinen Teil der Einsaat bereits vorhanden gewésen sein, da ein zu großer Bruchteil der Einsaat anwächst. Sät man z. B. in eine Petrischale $35 \mathrm{~mm}^{3}$ Zellen ein und läßt sie unter Zusatz von 50 Vol.-\% inaktiviertem Kälberserum wachsen, so beträgt die Ernte nach 24. Stdn. 62\% der Einsaat und nach 48 Stdn. $100 \%$ der Einsaat. Die Idee, daß der Gärungsstoffwechsel der Krebszellen durch Selektion entsteht, muß also nunmehr durchaus aufgegeben werden.

\section{Zusammenfassung}

Aus unsern Versuchen folgt, daß in den embryonalen Zellen ein chemischer Mechanismus vorliegt, der den Gärungs-Stoffwechsel schnell und vererbbar erzeugen kann, durch einen Vorgang, für den Mutation nicht der richtige Ausdruck wäre. Es sieht so aus, als ob die Nucleinsäuren der embryonalen Zellen ihre lange anaerobe Vorgeschichte noch nicht vergessen haben.

Unsere Versuche bestätigen ferner von neuem, daß der embryonale Stoffwechsel ein reiner Oxydations-Stoffwechsel ist. Nichts ist obligater aerob, als die embryonale Zelle der höheren Tiere, die ja gerade dem Ersatz der Gärung durch ıdie Atmung ihre Höherentwicklung vendankt ${ }^{3}$. Nur Krebszellen ${ }^{4}$ und sie alleine sind im Körper der höheren Tiere des Lebens ohne Sauerstoff fähig.

3 J. R. Nursall, Nature [London] 183, 1170 [1959].

$4 \mathrm{O}$. W ARBurg, The Metabolism of Tumors, London (Constable) 1930 und die folgende eine interessante Konsequenz bei R. M. Malmgren u. C. C. Flamigan, Cancer Res. 15, 473 [1955]. Infiziert man gesunde Mäuse mit Tetanussporen, die nur sauerstofflos keimen können, so bleiben die Mäuse gesund. Infiziert man aber Tumormäuse mit Tetanussporen, so keimen die Sporen zwischen den Krebszellen aus, und die Tiere gehen an Tetanus zugrunde. 